\title{
Slovenski misijonar Marko Anton Kappus in pokristjanjevanje Nove Španije
}

Ključne besede: Marko Anton Kappus, Nova Španija, jezuitski misijoni, 17. in 18. stoletje, pokristjanjevanje

DOI: 10.4312/ars.11.2.311-330

»Stari svet se mi skoraj dozdeva kot stvar,

o kateri se mi je pred davnim časom samo sanjalo."

(Iz pisma bratu 20. junija 1699) $^{1}$

Letos mineva 300 let od smrti prvega slovenskega misijonarja v Mehiki Marka Antona Kappusa (12. april 1657-30. november 1717). Jezuit, doma iz Kamne Gorice, se je v Novi svet odpravil v okviru vélikega pokristjanjevalskega projekta Družbe Jezusove in ostal tam do konca svojega življenja. Deloval je v času, ko meje Nove Španije še niso bile dokončno zarisane: sto osemdeset let po padcu Tenochtitlana pod vodstvom Hernána Cortésa ter osvajalskih odpravah njegovih naslednikov se je kolonialni sistem že dodobra razvil in utrdil, toda na skrajnem severozahodu današnje Mehike in jugu današnjih Združenih držav so ostala ozemlja, na katerih so živela indijanska ljudstva, ki si jih španska krona še ni podredila. ${ }^{2} \mathrm{~V}$ procesu kolonizacije teh težko dostopnih predelov je jezuitski verski red odigral odločilno vlogo.

V prispevku bomo skozi pogled Marka Antona Kappusa podrobneje osvetlili pomen, ki so ga misijonarji pripisovali enemu temeljnih opravil svojega duhovnega poslanstva, podeljevanju krsta. Pokazalo se bo, v kako zelo različnih, negotovih, burnih in pogosto protislovnih razmerah so delovali, s kakšnimi objektivnimi in subjektivnimi izzivi so se srečevali ter kako globoka sta bila njihova vera in prepričanje $\mathrm{v}$ upravičenost svojega početja. $\mathrm{V}$ tem kontekstu bomo predstavili vsebino pisma, $\mathrm{v}$ katerem se izriše nepričakovan in doslej nepoznan odtenek v odnosu slovenskega jezuita do njegovega sodelavca, slovitega tirolskega misijonarja, raziskovalca in kartografa Francisca Eusebia Kina.

1 Nem. izvir. in angl. prev. v: Stanonik, 1989, 45; slov. prev. v: Zaplotnik, 2016, 48-52.

2 Sinaloa, Sonora in Spodnja Kalifornija ter južni del Arizone. 


\section{Jezuitski misijoni v Novi Španiii}

Katoliška cerkev je od začetka sodelovala pri raziskovalnih in osvajalskih odpravah ter je bila poleg krone najpomembnejša institucija kolonialnega sistema. Posvetni duhovniki so skrbeli predvsem za bogoslužje v mestih, torej za španske priseljence in kreole, pokristjanjevanje poganskih staroselcev pa so večinoma prevzeli verski redovi; sprva so bili to frančiškani in dominikanci, nato so se jim pridružili še jezuiti. Prvi misijonarji Družbe Jezusove so v današnjo Mehiko prišli v drugi polovici 16. stoletja. Leta 1572 so ustanovili jezuitsko misijonsko provinco v Ciudad de Méxicu, nato pa so se njeni člani podali v še neodkrite predele na severu in severozahodu, da bi evangelizirali tam živeča indijanska ljudstva in jih tako pripravili na življenje v novi krščanski družbi kot podanike čedalje obsežnejšega španskega kraljestva. Tako kot v Južni Ameriki na področju današnjih držav Paragvaja, Brazilije, Argentine in Urugvaja so bili tudi na severu Mehike misijoni najpomembnejša mejna institucija španskega imperija (Hausberger, 1997, 63) oz. "vmesna institucija med konkvisto in kolonizacijo« (Salmón, 1991, 21).

Področje delovanja so počasi, a vztrajno širili, hkrati in v soodvisnosti z ekspanzijo kolonialnega sistema. Od prvih misijonskih postaj ob reki Sinaloa leta 1591 so v stotih letih prodrli v Sonoro, Durango in Chihuahuo, v 18. stoletju pa še na jug Arizone, v Spodnjo Kalifornijo in na gorovje Narayit (Slika 1).

$\mathrm{Na}$ teh obrobnih področjih, kjer konkvista $\mathrm{z}$ vojaškimi metodami zaradi nomadskega načina življenja in bojevitosti avtohtonih ljudstev ni bila učinkovita, so jezuiti v dvesto letih zgradili učinkovit, do podrobnosti izdelan in utečen verski in družbenogospodarski sistem. Prva faza "civiliziranja» je bila nomadske in polnomadske prebivalce zbrati $\mathrm{v}$ stalnih naseljih ter jih spodbuditi $\mathrm{k}$ načrtnemu poljedelstvu in živinoreji. Proizvodnja hrane je pripomogla k ohranjanju stabilnosti naselja, ki je bila pogoj za evangelizacijo - misijonarji so lahko poganske Indijance naučili osnov katoliške vere in uskladili njihovo vsakdanje vedenje s krščansko moralo (Ortega Noriega, 1993, 52). Nekateri staroselci so se odzvali zaupljivo in se podredili novemu redu, drugi pa so se predvsem na začetku silovito upirali poseganju v svoje ozemlje in način življenja, zato so oblasti vzpostavile mrežo vojaških garnizij (presidios) v utrjenih taborih, iz katerih so poklicni vojaki po potrebi prišli na pomoč misijonarjem, zatrli upore ter zavarovali obstoječe španske in indijanske vasi. ${ }^{3}$

Sprva so bili misijonarji, razen redkih izjem, Španci, vendar je bilo teh zaradi širjenja misijonske mreže kmalu premalo. Zato je bil leta 1664 med Španijo in Družbo Jezusovo sklenjen dogovor, da jih je lahko četrtina iz držav, ki so dinastično povezane

3 O spregi misijon-presidio gl. Ortega Soto v: Ortega Noriega, del Río, 2010, 185-241; Schwaller, 2001; Hausberger, 2015. 
s špansko krono (Nemčija, Avstrija in Češka) (Stanonik, 1987). In tu se začne zgodba o slovenskem misijonarju. Leta 1680 in 1681 je na pot čez Atlantik odplula prva skupina 23 jezuitov iz srednje Evrope, v kateri je bil tudi Francisco Eusebio Kino (1645-1711), naslednja skupina, ki se ji je pridružil Marko Anton Kappus, pa je odpotovala sedem let pozneje. Kappus je prve misijonske zadolžitve prevzel aprila 1688 med Indijanci Ópata in Eudeve v Cucurpeju v Sonori (Slika 1).

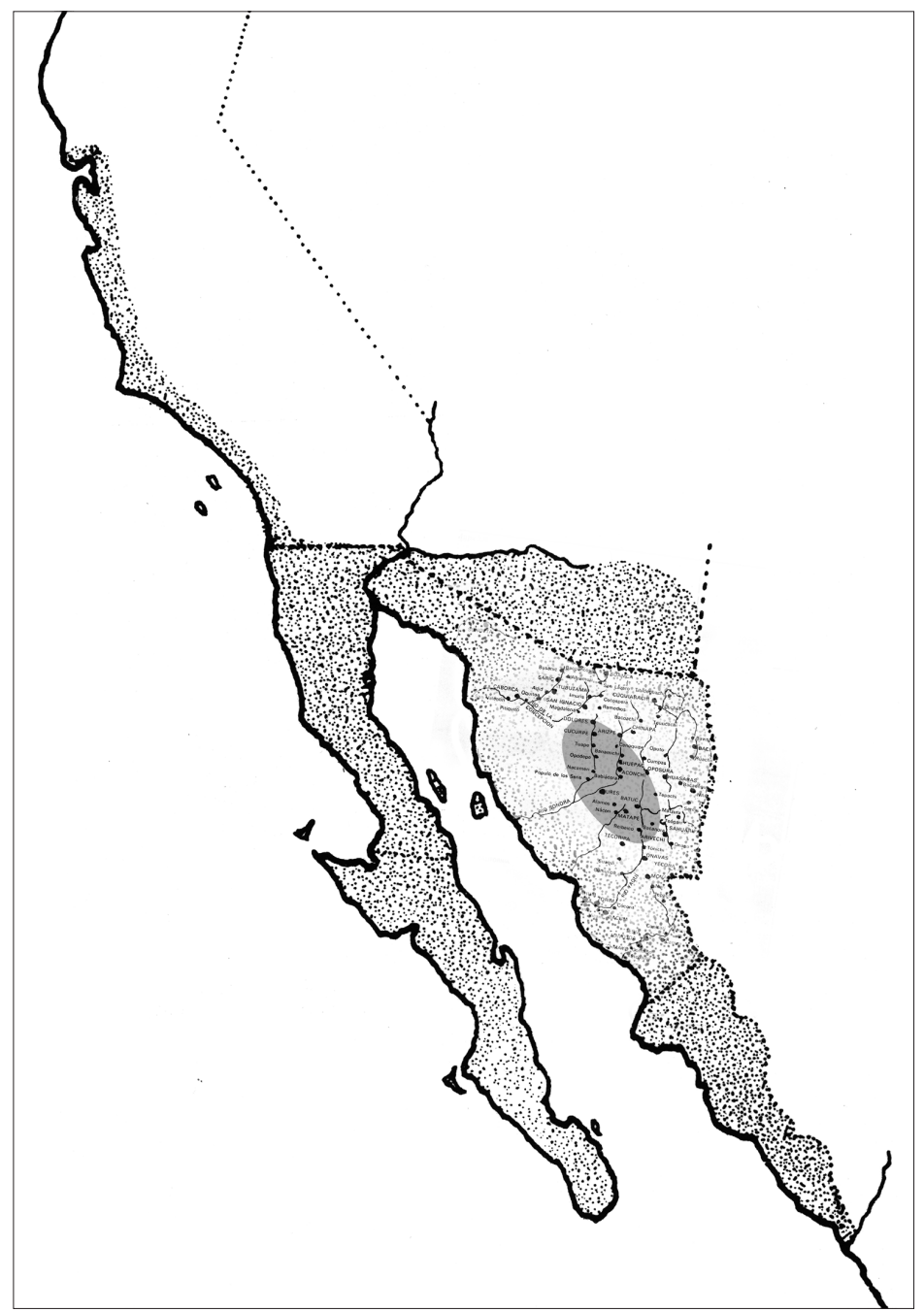

Slika 1: Področje jezuitskih misijonov na zahodu in severozahodu Mehike, 1591-1767. Vir: Ortega Noriega, 1993, 12. Elipsa označuje območje misijonov

Cucurpe, Mátape in Arivechi, v katerih je služboval Marko Anton Kappus (dodala M. Š.). 


\section{Kappusova pisna zapuščina}

Najpomembnejši vir podatkov o delovanju misijonov in kolonialnem družbenopolitičnem kontekstu so zapisi misijonarjev, predvsem korespondenca, pa tudi geografska, zgodovinska, naravoslovna poročila in pripovedi ter življenjepisi sodobnikov. Treba je poudariti, da pri tem pisanju ne gre za osebno nagnjenje posameznika, temveč za verno sledenje smernicam, ki jih je začrtal ustanovitelj reda Ignacij Loyolski (1492-1556). Zapisovanje in dopisovanje je bilo namreč ključno sredstvo za izgradnjo in ohranjanje enotnosti in identitete verske skupine, katere člani so se razpršili po dotlej poznanem svetu (Torales Pacheco, 169). Misijonarji so si redno dopisovali med seboj znotraj province, pa tudi $z$ drugimi člani jezuitskega reda v Evropi in drugih misijonih. Podrobno so se obveščali o rezultatih svojega dela in nadrejenim pošiljali poročila, ki so potovala naprej po hierarhični lestvici do Rima. Brez te trdno stkane in razpredene komunikacijske mreže projekt evangelizacije in $\mathrm{z}$ njo tesno povezane kolonizacije ne bi mogel doseči tako pomembnih zgodovinskih razsežnosti, kot jih je. Hausberger na sistem delovanja Družbe Jezusove gleda z vidika globalne zgodovine in jezuitske misijonarje imenuje "zgodnji agenti globalizacije« (Hausberger, 2015, 9; prim. Classen, 2013, ix-x).

Večina misijonarjev, tudi Kappus, je poleg redne notranje mreže vzdrževala tudi stik $\mathrm{z}$ »zunanjim« svetom, sorodniki, dobrotniki, prijatelji. Ta pisma so bolj razgibana in sproščena, saj so $\mathrm{v}$ njih naslovnikom na drugi strani oceana poskušali čim bolj približati »novi« svet in so zato polna slikovitih opisov narave, podnebnih značilnosti, rastja, živali, staroselcev in njihovega načina življenja ter osebnih izkušenj z njimi.

Veliko zapisov jezuitskih misijonarjev je zbranih in ohranjenih $\mathrm{v}$ delih, ki so jih napisali sami misijonarji in jih nekateri objavili še za časa svojega življenja ali pa so to pozneje storili drugi - tako na primer del Kappusove korespondence najdemo v Kinovem delu Crónica de la Pimería Alta: Favores Celestiales -, večina gradiva pa je razpršena v arhivih in knjižnicah v Rimu, Sevilji, Mehiki, Združenih državah Amerike in državah, iz katerih so bili posamezni člani. Tudi dosedanji slovenski in tuji raziskovalci življenja in dela Marka Antona Kappusa - Stanonik, Nabergoj, Maver, Zaplotnik, Hausberger - so uspeli locirati dragocene drobce njegove pisne zapuščine na različnih koncih sveta. ${ }^{4}$

4 Eno od dveh pisem bratu je leta 1728 izšlo v zbirki jezuitskih pisem Der neue Welt-Bott; dopis, s katerim je Kappus Kinov zemljevid Kalifornije poslal na Dunaj, je bil prvič objavljen leta 1707 v nemški reviji Nova litteraria Germaniae; štiri pisma, ki jih je poslal različnim prejemnikom v domovino, so v Arhivu Slovenije; eno, ki ga je napisal jezuitskemu generalu Noyellu pred odhodom v misijone, je v Arhivu Družbe Jezusove v Rimu; prvo znano pismo Eusebiu Franciscu Kinu, ki pa ga ta v Favores Celestiales ne omenja, je v Zgodovinskem arhivu zakladnice v Ciudad de Méxicu; naročilnica potrebščin za misijon je v Narodnem arhivu v Ciudad de Méxicu; pismo mehiškemu provincialu Almonazirju hrani Univerzitetna knjižnica Yale; prepis podatkov iz krstne knjige za kraja 
$\mathrm{Na}$ tem mestu velja poudariti, da je slovenski misijonar pisal $\mathrm{v}$ treh jezikih, odvisno od tega, na koga jih je naslavljal. Štiri pisma so v latinščini: po eno namenjeno članom jezuitskega reda v Rimu, Ljubljani in na Dunaju ter eno slovenskemu pravniku in kulturniku Janezu Gregorju Dolničarju. S sorodniki si je dopisoval v nemščini; ohranjeni sta dve pismi bratu Janezu in eno teti, opatinji samostana v Škofji loki. S sobrati in nadrejenimi ter s posvetnimi upravnimi organi v Novi Španiji pa se je sporazumeval v kastiljščini; v tem jeziku so vsa pisma Eusebiu Kinu ter pismo provincialu Diegu de Almonazirju, v katerem Kina kompromitira in ki ga bomo razčlenili v nadaljevanju. Poleg navedenih treh jezikov je znal tudi italijansko, ker je bil njegov oče po rodu Italijan in ker je dve leti študiral v Milanu. Doma so nedvomno govorili in brali (tudi) slovensko in etnično so se imeli za Kranjce (Maver, 2016). Ob vstopu v jezuitski red leta 1676 je devetnajstletni novic med znanji jezikov slovenščino navedel na prvem mestu, šele nato nemščino in latinščino (Stanonik, 1999). K petim jezikom, ki jih je bodoči misijonar uporabljal v Evropi, je treba prišteti še jezik Indijancev Ópata v Sonori, ki se ga je naučil ob delu z njimi.

V primerjavi z ohranjenim opusom nekaterih vidnejših misijonarjev, ki so zapustili izčrpne kronike in znanstvena besedila z različnih področij, je zbirka Kappusovih besedil količinsko skromnejša, a njihova vsebina je dovolj pestra in nabor njihovih naslovnikov dovolj razvejan, da je mogoče na podlagi informacij, ki jih vsebujejo, sestaviti dokaj celostno sliko ne le njegovega misijonarskega življenja, temveč tudi širšega konteksta, v katerem je potekalo osvajanje Mehike, in oceniti vlogo, ki so jo v tem procesu odigrali jezuitski misijonarji.

V doslej objavljenih študijah so bili predstavljeni različni vidiki Kappusove življenjske poti: družinsko ozadje, šolanje in nato poučevanje v jezuitskem kolegiju, študij v Gradcu in Milanu, poznanstva $z$ verskimi in posvetnimi intelektualci, prošnje za odhod v misijone, potovanje iz Cádiza do končne destinacije, življenjske razmere v Sonori, udomačitev med Indijanci, njegov odnos do njih in skrb zanje, občudovanje narave in njenih darov, zdravstvene tegobe, upor Indijancev Tarahumara, avtorstvo pesnitve $\mathrm{v}$ latinščini, napredovanje $\mathrm{v}$ hierarhiji do mesta rektorja kolegija in nato očeta vizitatorja za Sonoro. Najpogosteje pa je omenjen prav kot prijatelj in tesen sodelavec Eusebia Francisca Kina pri zahtevnih odpravah proti Spodnji Kaliforniji in kot »pooblaščenec« za posredovanje njegovega zemljevida Kalifornije kot polotoka (in ne otoka, kot je veljalo dotlej) na Dunaj leta $1701 .^{5}$

Cucurpe in Saracachi je dostopen na spletni strani National Park Service. Za nekaj pisem obstajajo reference, vendar jih (še) niso odkrili; enako velja za edino znano Kappusovo (potencialno) literarno besedilo, pesnitev Enthousiasmus.

5 V slovenski prostor je najobsežnejše védenje o Marku Antonu Kappusu prispeval Janez Stanonik v vrsti člankov v angleškem jeziku, ki jih je od leta 1986 do 2007 objavil v reviji Acta Neophilologica. Stanonikovo delo je z novimi izsledki nadgradil Tomaž Nabergoj v študijah v angleškem, slovenskem 


\section{Per maiorem Dei Gloriam}

Misijonarji so presojali svet iz verske perspektive. »Svet Marka Antona Kappusa je svet, ki mu neposredno vlada Bog, « zapiše Stanonik (1990). V pismih se ob vseh dogodkih, dobrih in slabih, sklicuje na vseprisotnost božje volje: »vsa hvala Bogu, smo kar zdravi« (patru Michaelu dell Potau z ladje na poti iz Cádiza na Kanarske otoke 10. julija 1687), ${ }^{6}$ »[n]aj naš Gospod Bog pomaga pri tej zadevi« (Eusebiu Kinu 25. novembra $1690 \mathrm{v}$ zvezi s težavami zaradi pomanjkanja vode, umiranja ljudi in izkoriščanja Indijancev za delo na posestih in v rudnikih), ${ }^{7}$ "[m]oji in sosednji Indijanci pa, hvala predobremu Bogu, žive v miru« (Dolničarju 20. januarja 1691 po uporu ljudstva Tarahumara) ${ }^{8}$ itd. Pri tem ne gre (le) za retorične formulacije, ampak za iskreno pobožnost, za globoko vero v božjo vsemogočnost in milost. Celo nasilna smrt misijonarja, ki so ga prerešetale indijanske puščice, je del neoporekljivega božjega načrta in potemtakem za nekaj dobra. Takole piše Kinu 7. aprila 1695 ob smrti misijonarja Francisa Javierja Saete:

Upam, da se bo naš Gospod v svojem božjem Veličanstvu ozrl na to nedolžno žrtev in pospešil spreobrnjenje mnogih duš. Zelo močno upam, da bo vse to zlo izdatno obrodilo veliko in velike koristi. Naj to stori Njegovo božje Veličanstvo [...] (Kino, I, IV, II, 113. Prev. M. Š.).

O tem, kako močno je verjel v poslanstvo (lat. missio), katerega bistvo je bilo širjenje božje besede in reševanje duš pred pogubo, priča že vztrajnost, s katero je po prvi neuspešni prošnji za odhod v misijone še v drugo poskušal prepričati - tokrat uspešno - provinciala Charlesa de Noyella o svoji trdni predanosti vzvišeni ideji: »[K] ot prosilec najponižneje poklekam pred prečastitega očeta in ga spet in spet vztrajno prosim za milost, da bi smel odpotovati [...] in posvetiti življenje delovanju za Božjo slavo in blagor bližnjih. «9 Iz perspektive Družbe Jezusove gre torej pri osvajanju novih področij in spreobračanju poganskih ljudstev v krščanstvo za »duhovno osvojitev« oz. odrešitev, ne za podrejanje in še manj zatiranje ali izkoriščanje avtohtonih prebivalcev.

in španskem jeziku $(1998,1999,2007,2009,2010) \mathrm{v}$ domačih in tujih publikacijah. Igor Maver je v Stanonikovem zborniku (2016) objavil pregledni prispevek o dotedanjih raziskavah in dodal nekaj še neobjavljenih dokumentov, med drugim Kappusovo pismo provincialu Almonazirju. Istega leta je izšla dvojezična knjiga v slovenščini in angleščini, v kateri je Peter Rožič uredil in iz angleščine deloma prevedel spis, ki ga je o Kappusu napisal slovenski izseljeniški duhovnik in misijonar Janez Zaplotnik (1883-1978). Kappusa omenjajo tudi tuji raziskovalci jezuitske tematike; najpomembnejši je Bernd Hausberger, ki je v biobibliografiji jezuitskih misijonarjev iz Srednje Evrope (1995) zbral seznam 40 Kappusovih zapisov, v glavnem pisem (prim. Nabergoj, 1998); večina teh dokumentov še čaka na objavo. Classen $(2013,2014)$ v glavnem sledi Hausbergerjevim in Stanonikovim izsledkom.

6 Lat. izvir. in angl. prev. v: Stanonik, 1987; slov. prev. v: Zaplotnik, 2016, 15-17.

7 Špan. izvir. v: Nabergoj, 1998; slov. prev. v: Zaplotnik, 2016, 29.

8 Lat. izvir. in angl. prev. v: Stanonik, 1990; delni slov. prev. v: Zaplotnik, 2016, 33-34.

9 Lat. izvir. in slov. prev. v: Maver, 2016. Poudarila M. Š. 
To pa je seveda glavni oz. edini cilj kolonialnega sistema, v katerega je bila formalno vpeta tudi sama. Hausberger pojasnjuje, da so jezuiti, čeprav niso odobravali vsega, kar se je dogajalo, svoje nelagodje podrejali svojemu vélikemu cilju - ekscesom kolonizacije so nasprotovali, kadar so ogrožali uspeh spreobračanja, ker so evangelijskemu sporočilu odvzemali vsakršno kredibilnost in staroselcem osovražili krščansko družbo, a dejstvo je, da sami kolonizaciji niso nasprotovali (Hausberger, 2015, 202-203).

\section{Podeljevanje krsta}

Ni podatkov o tem, koliko ljudi je Kappus krstil v skoraj tridesetih letih službovanja v Sonori. Ohranjena je le krstna knjiga za kraja Cucurpe in Saracachi, v kateri je zavedenih dvajset otrok, ki jih je tam krstil med letoma 1689 in 1694 . Vsak vnos sestavljajo datum, ime in priimek krščenca ter staršev, botra ali botre in duhovnika. Vsa imena Indijancev so krščanska, priimki pa večinoma indijanski. Enkrat je dodan tudi pripis:

Michaela: 23. septembra [1689] sem svečano krstil Miguelo, posthumno hčer Manuela Chiguuma, volarja, in Maríe Nidanu. Botra Lucia Moruisar. Marcos Antonio Kappus, S.J., Duhovnik v službi njegovega Veličanstva. ${ }^{10}$

Med imeni drugih krščencev iz te evidence je tudi Francisca, ki je Kappusu še posebej ljubo. Frančiška je bilo namreč ime njegovi teti, opatinji samostana v Škofji Loki. V pismu, ki ji ga je pisal dobro leto po prihodu v Cucurpe, 30. aprila $1689,{ }^{11} \mathrm{ji}$ med drugim pove, s kakšnim veseljem je prvo deklico, ki jo je krstil v Novi Španiji, poimenoval Francisca in se ob tem svetem opravilu spomnil nanjo. Nečak prvemu od sedmih zakramentov tudi sicer posveti kar polovico razmeroma dolgega opisa svojega življenja med Indijanci. Glede na to, da piše redovnici, to ne preseneča, a hkrati potrjuje, s kolikšno predanostjo in odgovornostjo so misijonarji opravljali to nalogo. Pove, da so vsi njegovi Indijanci krščeni in da so prišli k njim v vas živet tudi pripadniki poganskih ljudstev Seri in Tepoke, ki hočejo ostati med njimi ter »sprejeti pravo vero in biti krščeni«. Med velikonočnimi prazniki jim je, »da bi ustvaril v njih željo po svetem krstu, krstil na njihove dolgotrajne in nujne prošnje kakšnih 20 otrok«. Naslednji dan, ko je odhajal, mu je sledilo še nekaj staršev s svojimi otroki, da bi jim jih krstil, kar je z velikim veseljem storil. S sosedom Eusebiem Kinom sta se nato odpravila še med pogane v dolino reke Himeris [Visoka Pimería]. Sprejeli so ju »z največjo ljubeznijo« in tam je krstil »61 odraslih in otrok, ki so se želeli pokristjaniti in so že bili tudi poučeni«, med njimi tudi enega poganskega poglavarja Indijancev. Za

10 Nav. in prev. po: Nabergoj, 2011. Podatki National Park Service (U. S. Department of the Interior), http://home.nps.gov/applications/tuma/Detail.cfm?Personal_ID=3804 [30. 9. 2017].

11 Nem. izvir. in angl. prev. v: Stanonik, 1986; slov. prev. v: Zaplotnik, 2016, 25-28, in delno v: Nabergoj, 2009. 
konec opiše še primer, v katerem je našel "posebno duhovno tolažbo«, ker je »rešil dva starca iz hudičevega žrela«: krstil je moža in ženo, ki zaradi svoje starosti nista mogla več »ne hoditi ne videti ne slišati«. Njuna pojava je naredila nanj izjemen vtis, saj pravi, da svoje žive dni še ni videl tako starih ljudi; po njegovem je bil »vsak od njiju star vsaj kakih 120 let« in »izgledala nista nič drugače kot živa smrt«. Ko sta privolila in dala znamenje, da hočeta biti krščena, ju je krstil za Adama in Evo.

V zgornjih opisih zbudijo pozornost formulacije, $\mathrm{v}$ katerih so posredno vsebovani pogoji, ki so jih morali izpolnjevati kandidati za krst: slovenski misijonar je krstil 61 odraslih in otrok, ki so že bili poučeni [o krščanski veri]; starca sta privolila in dala znamenje, da hočeta biti krščena; Indijanci si želijo ostati med njimi in sprejeti pravo vero; otroke krsti na dolgotrajne in nujne prošnje njihovih staršev itd. Izstopajo torej velika želja Indijancev po spreobrnitvi, njihovo poznavanje krščanskega nauka in ljubezen do "prejete prave vere«. Majhni otroci in novorojenci so bili namreč v krščansko občestvo sprejeti samo z običajnim krstnim obredom, odrasli pogani pa so se morali pred tem svečanim dejanjem odreči svojim verovanjem ter zavestno in prostovoljno sprejeti edino pravo vero. Cerkvene oblasti so že na prvem provincialnem koncilu v Ciudad de Méxicu leta 1555 duhovnikom izrecno prepovedale podeljevanje zakramenta krsta odraslim, »ki niso prej dovolj poučeni v naši Sveti Katoliški veri« in se niso »očistili« malikovanja in starih obredov; verjeti morajo, preden so krščeni, tako da »izrecno in vztrajno prosijo za spreobrnitev«. Izjema so samo tisti, ki jim preti skorajšnja smrt. Čas, ki naj se posveti poučevanju, pa je bil prepuščen »vesti duhovnikov«(Concilios ..., 1769, 43-44).

Ni veliko podatkov o tem, kako je potekala priprava, a bila je bolj ali manj kratka, odvisno od okoliščin (Ricard, 1986, 167). Ker se je uspešnost misijonov merila v številu novih kristjanov (in s tem kraljevih podanikov), se je dogajalo, da so se duhovniki v želji, da bi spreobrnili čim več staroselcev, pri podeljevanju zakramenta prenaglili, njihovi neofiti pa so nato prikrito ali celo povsem odkrito še naprej živeli po svojih starih običajih. Nekateri misijonarji so še ob koncu 17. stoletja koncilska pravila precej ohlapno tolmačili in jih prilagajali razmeram na terenu.

Med ljudstvi na ozemlju Sonore, kjer sta delovala Kappus in Kino, misijonarji s pokristjanjevanjem niso imeli velikih težav, kakor je mogoče sklepati tudi iz Kappusovega pisma teti Frančiški. To gre v veliki meri pripisati zelo preprostim družbenim in verskim sistemom, $v$ katerih so živela (povsem drugače kot na primer visoko razviti azteška in majevska kultura $\mathrm{v}$ osrednjem delu Mehike). Ker so bila večbožna, so krščanskega boga sprva sprejela kot enega med mnogimi, a tudi resnica, da je bog en sam, zanje ni bila nesprejemljiva. Kino v Favores Celestiales njihovo naklonjenost novi veri opiše takole: 
[Tukajšnji] ljudje ne poznajo posebnega malikovanja ali drugih ločin, ki bi jih bilo posebno težko izkoreniniti [...], in čeprav zelo častijo sonce kot nekaj zelo veličastnega, jih je z lahkoto podučiti in sprejmejo nauk, da je Vzvišeni Bog vsemogočen in da je on tisti, ki je ustvaril sonce in luno in zvezde in vse ljudi in ves svet in vsa bitja (Kino, V, IV, XI, 253. Prev. M. Š.).

Tudi Kino v svoji kroniki tako kot Kappus v pismu sorodnici vseskozi ponavlja, da Indijanci sami vztrajno prosijo krst zase in za svoje otroke ter radostno sprejemajo novo vero. A njegov spodbudni ton ni nujno zmeraj povsem veren odraz resnične situacije, temveč ga gre pripisati (tudi) učinku, ki ga je želel z njim doseči. Kroniko Favores Celestiales je namreč posvetil španskemu kralju Filipu V. ${ }^{12}$ in $\mathrm{z}$ opisom vseh »nebeških naklonjenosti«, ki se kažejo v vedno novih osvojitvah in spreobrnitvah, bi neutrudni misijonar rad vzbudil kraljevo pozornost ter pozornost oblasti na področju Sonore in Pimeríe, da bi izdatneje podprla njegov načrt širjenja misijonov v Spodnjo Kalifornijo (Hernández, Sánchez-Barba, 1958, 94). ${ }^{13}$

V resnici pri spreobračanju ni šlo vedno vse tako gladko, kakor bi rad prikazal Kappusov sodobnik. Misijonarji so morali poleg jezikovnih ovir pogosto najprej premagati nezaupanje ali odkrito nasprotovanje staroselcev novemu načinu življenja in novi veri. Nekateri so ceremonijo sprva na primer povezovali s smrtmi, ki so jih povzročale čedalje pogostejše epidemije (Hausberger, 2002, 124). Poleg tega so jih proti jezuitom zaradi rivalstva podpihovali lastniki rudnikov srebra in latifundisti. Kino v Favores omenja laži, ki jih Španci o njih tvezejo Indijancem: na primer, da s svetim oljem ubijajo ljudi, da bodo z načrtno živinorejo izsušili napajališča, da jim trosijo lažne obljube itn. Kolonizatorji so poskušali ugledu jezuitov škodovati tudi pri civilnih oblasteh in s tem zmanjšati njihov vpliv. Kino zabeleži, da so ob veliki noči leta 1687 »zlobni jeziki« sprožili lažno govorico, da je skupina Indijancev iz novih naselij pred krstom pobegnila v divjino, o čemer je župan Reala de San Juan ${ }^{14}$ pisal celo očetu vizitatorju (Kino, I, II, V-VI, 103). V takšnih razmerah so misijonarji težko vzdrževali trhlo ravnovesje med pričakovanji kolonov in zaupanjem Indijancev.

Ker so duhovniki smeli krstiti samo, če so kandidati izkazali popolno razumevanje krščanskih naukov in jih z vsem srcem sprejeli, so se soočali z velikimi izzivi, kako to

12 Istemu kralju je Kappus leta 1708 posvetil pesnitev Enthousiasmus, v kateri ga slavi in mu s tem izraža lojalnost.

13 Kinova motivacija je torej povsem pragmatična, podobno kot je veljalo za prva poročila konkvistadorjev, na primer za Cartas de relación, ki jih je Hernán Cortés s svoje osvajalske odprave po Mehiki pošiljal kralju Karlu V.

14 Real [de minas] je občno ime za rudarski kompleks (rudnik s pripadajočimi objekti), v katerem so po t. i. sistemu »repartimiento« morali delati Indijanci iz misijonov (gl. Ortega Noriega, 1993, 58). O problemu izkoriščanja »teh revežev« piše tudi Kappus v pismu Kinu 25. novembra 1690 (gl. Nabergoj, 1998, 1999, in Zaplotnik, 2016, 29-30). 
doseči. Da bi pridobili njihovo zaupanje, so uporabljali "mehke« metode in zglede. Čeprav so poskušali izkoreniniti določene navade, so jih tudi tolerirali in se jim prilagodili. V jezuitskem duhu se je moral namreč misijonar postaviti v kožo drugega in vsa "politika" misijona je temeljila na dialogu (Navajas Josa, 2011, 105). Očetje so se bolj ali manj uspešno naučili jezika svojih »sinov«, da so se lahko sporazumevali pri vsakdanjih opravilih in jim približali osnovne verske pojme. Pozitivne učinke krsta so pogosto podkrepili z dodatnimi ugodnostmi, na primer s podarjanjem hrane in oblačil krščencem in njihovim družinam. Predvsem pa so dotedanje nomade in polnomade poskušali o prednostih sedentarnega življenja $\mathrm{v}$ redukcijah ${ }^{15}$ in milosti krščanskega boga prepričati s tem, da so jih naučili učinkovitega poljedelstva in živinoreje.

Nekatera ljudstva so se hitro privadila na nove okoliščine in sprejela tudi krščanstvo (tak primer so prav »Kappusovi« Indijanci Ópata in Eudeve), nekatera - na primer Seri in Tepoka, tudi nekatere skupine Pima - se niso povsem ustalila, temveč so se občasno ali za stalno vračala $\mathrm{v}$ odmaknjene predele, največje preglavice pa so očetom povzročali Indijanci Tarahumara, ki se vsem prizadevanjem navkljub niso uklonili. Tudi Marko Anton Kappus je posredno ali neposredno izkusil razlike v »civiliziranosti« teh ljudstev. Videli smo, kako je v pismu teti Frančiški z zadovoljstvom pripovedoval o sožitju v misijonski postaji Cucurpe in pozitivnem odnosu staroselcev do krščanstva. A le leto zatem je bil priča posledicam srditega upora Indijancev Tarahumara, ki so skovali »bogokletno zaroto, da se popolnoma otresejo jarma krščanske vere«, opustošili več misijonov, zažgali cerkve in umorili dva patra. ${ }^{16} \mathrm{O}$ tem je deset mesecev pozneje, 20. januarja 1691, še vedno pretresen poročal bratu Janezu ter istega dne tudi Janezu Gregorju Dolničarju. Po podrobnem opisu grozodejstev, ki so jih zagrešili »ti naščuvani divjaki«, posebej izpostavi miroljubnost in pobožnost svojih varovancev:

Moji [Ópata in Eudeve] in sosednji Indijanci [Seri, Tepoka, Pima] pa, hvala predobremu Bogu, žive v miru in mnogo bolj ljubijo prejeto pravo vero ter niso tako divji in zverinski kot Tarahumarci, ki nikdar ne nehajo očetom misijonarjem nuditi izrednega polja za potrpežljivost, «17

zapiše v pismu Dolničarju. Bratu pohvali še njihovo močno vero, za katero so pripravljeni umreti, ter brezpogojno vdanost njemu, svojemu duhovnemu očetu.

A čez nekaj let so tudi »sosednji Indijanci« [Pima] izraze vdanosti zamenjali s srditim sovraštvom. Ljudstva Pima so naseljevala skrajni rob osvojenih ozemelj Visoke Pimeríe severno in severozahodno od Kappusovih misijonov. Prvi, ki je prišel v stik

15 Šp. izraz reducción (iz lat. reducti, »peljani«) pomeni naselje ameriških Indijancev, spreobrnjenih ("pripeljanih«) v katolicizem (Diccionario María Moliner). Redukcije so bile ločene od španskih naselij in so osnova jezuitskih misijonov.

16 O uporih staroselcev na severu Nove Španije gl. Salmón, 1991; prim. Stanonik, 1998.

17 Lat. izvir. in angl. prev. v: Stanonik, 1990; delni slov. prev. v: Zaplotnik, 2016, 33-34. 
z njimi, je bil Eusebio Francisco Kino. Njegovo prodiranje na ta odročna puščavska področja je bilo bolj rezultat njegove osebne zavzetosti kot organizirane ali vodene politike španske krone in Družbe Jezusove. Nadrejene je nenehno pozival, naj mu pošljejo okrepitve, in čeprav korespondenca kaže, da so ga generali Družbe podpirali v njegovih prizadevanjih (Navajas Josa, 2011, 100), so novi očetje prihajali prepočasi, tako da je bil pri svojem napornem evangelijskem delu prepuščen sebi in občasni pomoči sodelavcev iz sosednjih misijonov, tudi Kappusa.

\section{Kritika Kinovih pokristjanjevalskih metod}

Kappus v pismu teti Frančiški omeni, da so Kinovi Indijanci sicer še pogani, »toda večina izmed njih si zelo prizadeva, da se pripravi za prejem svetega krsta«. O tem se je prepričal, kot smo videli zgoraj, ko je soseda za veliko noč 1689 spremljal k njim. Kinovi varovanci so bili gotovo videti zelo naklonjeni novi veri, vendar se zdi, da razlogi za njihovo vnemo niso bili (samo) duhovni, temveč (tudi) zelo praktični.

Šest let pozneje, 28. julija 1695, je Kappus, takrat že rektor rektorata Nuestra Señora de los Dolores, pisal očetu provincialu Diegu de Almonazirju v Ciudad de México. ${ }^{18}$ Pismo je odgovor na poziv predstojnika s 27. septembra 1694, naj kot vodja misijona pošlje redna sredstva za provinco. ${ }^{19}$ Slovenski jezuit je naročilo sicer takoj izpolnil in odposlal prispevek, vendar se v pismu opravičuje, da je ta zelo skromen, ker »na tem koncu preživljajo katastrofalne čase zaradi vstaje sovražnikov«. Šlo je za dobro dokumentiran prvi upor ljudstva Pima, ki je izbruhnil konec marca 1695. Kappus domneva, da je oče provincial že po drugih poteh obveščen o nemirih v Pimeríi, vendar želi izpolniti svojo dolžnost in tudi sam podrobno popisati nesrečne dogodke. A preden preide $\mathrm{k}$ jedru poročila, torej poteku upora, brez okolišenja pove, kaj je po njegovem krivo za tolikšen bes »teh nečloveških zveri«.

Provincialu sporoča, da se mu način spreobračanja nikoli ni zdel ustrezen niti ni imel trdno postavljenih temeljev, zato se je bal posledic: »[O]d nekdaj sem slutil usodno pogubo, na kar sem vedno opozarjal vse neposredne in posredne nadrejene, kar jih je bilo v mojem času. « Nato opredeli ključno napako: po eni strani podkupovanje Indijancev $\mathrm{z}$ darili in po drugi površnost pri seznanjanju bodočih kristjanov s krščanskim naukom ter posledično podeljevanje krsta brez zagotovila, da bodo krščenci živeli v skladu z načeli svete vere:

18 Transkripcija izvirnega besedila v: Maver, 2016. (Prev. M. Š.) Faksimile je dostopen na spletni stani Benecke Rare Book \& Manuscript Library: http://brbl-dl.library.yale.edu/vufind/Record/3444258 [30. 9. 2017].

19 Očetje so morali iz misijonov pošiljati del prihodka v srebru na sedež province kot prispevek redu ali za plačilo naročilnic, s katerimi so naročali blago in potrebščine za misijon (Ortega Noriega, 1993, 57). 
[V]sa pozornost pri pokristjanjevanju ${ }^{20}$ [Indijancev] Pima je bila od vedno usmerjena $\mathrm{v}$ prikupovanje $\mathrm{z}$ darovi in mesom, ob tem pa se je zanemarjalo bistvo, to je pridigati Evangelij in poučevati krščansko doktrino ter božje in cerkvene zapovedi. Posledica tega je bila, da so z veliko lahkoto sprejemali krst, ne da bi vedeli, da to nosi s sabo obvezo, da se naučijo skrivnosti vere [...], zapovedi, in da živijo krščansko.

Te napake pozneje ni mogoče popraviti, kajti ko so odrasli enkrat krščeni, so s tem zadovoljni in "ni pričakovati, da se bodo naučili tisto, kar bi se morali naučiti in vedeti prej«. Tako ostanejo v svoji poganski nevednosti in nikoli ne izpolnijo krščanskih obveznosti. Kappus ugotavlja, da Indijanci novo vero enačijo z nagrado, saj je bil priboljšek ali dar, ki jih je vlekel k sprejetju krsta, zanje »ne le spodbuda, temveč edini trden motiv, njihov cilj, njihovo vodilo, njihovo vse«.

Sledi nenavadno groba poimenska obtožba sodelavca in prijatelja Eusebia Francisca Kina, v katerem vidi izvirnega krivca za izbruh upora neofitov in njihovo pustošenje po Pimeríi: ${ }^{21}$

$\mathrm{Ne}$ govorim o vseh očetih misijonarjih, ki so doslej prišli spreobračat $\mathrm{v}$ Pimerío, ampak samo o očetu Eusebiu Franciscu Kinu; če bi pogane podučeval s tolikšno vnemo, s kolikršnimi željo, zanosom in lahkoto jih je krščeval, bi imela danes tako zelo iznakažena Pimería drugačen obraz.

Slovenski misijonar obžaluje, da je Kino pri nepremišljenem podeljevanju zakramenta izgubil mero in tako povzročil veliko škodo: »Ker pa je premogel več vneme kot preudarnosti in previdnosti, se je v tej nesrečni Pimeríi zgodilo toliko nepravilnosti in nesmislov, da jih je skoraj nemogoče prešteti«, na primer, da so krščeni celo prebivalci po naseljih, ki so od misijonov oddaljena več kot 50 in 60 milj, samo da bi Družba tja napotila nove očete.

Kino je s takim nepremišljenim ravnanjem očetom, ki so prišli za njim, naredil medvedjo uslugo, nadaljuje Kappus. Novim očetom je namreč v primerjavi z njim uspelo pokristjaniti začuda malo poganov, to pa zgolj zato, ker želijo opravljati svojo sveto dolžnost tako, kot je treba. Ob tem zaradi napačnih predstav, ki jih je tem ljudem vcepil Kino, naletijo na negodovanje in zmerjanje.

Ko poganom, ki jih želijo krstiti, poskušajo predstaviti obveznosti kristjanov, nujnost zakonov vere itn., je prvo, kar jim odgovorijo, da oče Kino od tistih, ki so prosili za krst, tega ni zahteval. In ker je bilo povsod, kamor so prišli

20 Uporabljen je španski glagol reducir. Gl. op. 15.

21 V angleškem povzetku vsebine pisma ob faksimilu (gl. op. 18) napačno piše, da je Kappus razočaran nad ohlapnostjo očetov, ki so prišli za Kinom, ne pa nad Kinovo. Od tod verjetno napačna interpretacija v: Maver, 2016. 
novi očetje, veliko takih, ki jih je krstil oče Kino na svoj način, so menili, da jih morajo kot kristjane nenehno obdarovati z obleko, mesom itn. Ker pa novi očetje nimajo sredstev za to, tudi če tu in tam imajo ali dobijo kakšno oblačilo kot miloščino, to ni dovolj, da bi jih zadovoljili, jih ti potem zmerjajo, da jim je oče Kino pogosteje dajal meso, bolj radodarno delil obleko in druge darove.

Kappus je prepričan, da je prav to vzrok, da so sicer »ne vsi, a mnogi« [...] »svojemu [novemu] duhovniku izkazovali tako malo ljubezni, malo časti, malo spoštovanja in skoraj nobene pokorščine«. Najhujši so bili v najbolj oddaljeni Tubutami. Če jih je oče nagovarjal, naj kaj postorijo za njegove potrebe, so mu odvrnili, da mora tudi on delati z njimi, niso mu hoteli pripravljati hrane in pasti živine. ${ }^{22} \mathrm{Ob}$ praznikih in nedeljah so samo redki prihajali k maši in veliko jih je še potem, ko so bili krščeni, živelo z dvema ali tremi ženami, pohajalo po bližnjih zaselkih in uživalo svobodo. Seveda tudi $\mathrm{k}$ verouku niso hodili. Jezni, ker niso bili deležni takega obilja mesa in darov, kot so pričakovali, da ga bodo, ko so sprejeli krščansko vero, so se poskušali otresti jarma skrbi za duhovnika bodisi s predrznim in nespoštljivim govorjenjem bodisi z dejanji, na primer tako, da so streljali s puščicami na živino, dokler se ni naveličal in jih pustil na svobodi. Ker pa kljub temu ni hotel oditi, so mu večkrat zagrozili, da bodo pokončali vse, kar ima, kobile, živino, delovodjo in celo njega samega. Tudi eksemplarična kazen, ki so jo izvršili enkrat s pomočjo Špancev, ${ }^{23}$ drugič pa sodnih organov iz misijonske postojanke Nuestra Señora de los Dolores, ni zalegla. Nasprotno, »kot stekli psi« so začeli sejati še večja grozodejstva in uresničevati grožnje. Najprej so pokončali čredo kobil in živine, nato pa ubili delovodjo, ki je bil »dober Indijanec, Ópata, ki je skrbel za vse očetovo, kot bi bilo njegovo ${ }^{24}$ ter še dva druga nedolžna Indijanca, ki sta bila slučajno z njim. Ubili bi tudi misijonarja, če ne bi tri ure prej zapustil vasi, ker ga je Kappus v pismu pozval, naj čim prej pride k njemu z vsem, kar lahko vzame s sabo. Uporniki so se pognali za njim, a ker ga niso dohiteli, so opustošili njegovo hišo, "razrezali na koščke cerkvene prte, si jih razdelili in si jih navesili na svoja gola in bogokletna telesa«. Potem so razdejali posest, pobili krave in teleta ter se po mili volji izživljali. Nazadnje so sklicali prebivalce bližnjih zaselkov na praznovanje in ples. Naslednji podvig je bila odprava v Caborco, kjer so 2. aprila, na velikonočno soboto, ubili očeta Francisca Javierja Saeto. ${ }^{25}$

22 Jezuiti niso fizično delali, ampak so svoje varovance učili novih opravil, organizirali delo in skrbeli za delovanje misijona. Indijanci so tri dni delali na zemlji misijona, ki je bila skupna last, tri dni pa na svojih parcelah (Ortega Noriega, 1993, 55).

23 V mislih ima presidio. Gl. op. 3.

24 Ob ustanavljanju novih misijonov so jezuiti pripeljali s seboj že pokristjanjene Indijance (v tem primeru Ópata), da so jim pomagali pri sporazumevanju in pri poučevanju verouka (Navajas Josa, 2011, 115). 
$\mathrm{V}$ drugih dveh tretjinah pisma podrobno popiše in komentira potek dogodkov od Saetove mučeniške smrti do trenutka, ko sestavlja pismo, 28. julija, še vedno sredi hudih nemirov. ${ }^{26}$

Kappus ni bil edini misijonar, ki je kritiziral Kinove površne metode pokristjanjevanja. ${ }^{27}$ Dejstvo je, da je Diego de Almonazir po tem uporu poklical Kina na sedež province pod pretvezo, da želi slišati poročilo o njegovih misijonih in hkrati organizirati srečanje s podkraljem glede sredstev za odpravo v Kalifornijo. V resnici pa je nameraval s tem ukrepom onemogočiti misijonarjevo nadaljnje sporno početje (Gómez Padilla, 2007, 84). Kino v Favores tudi sam piše o svojem potovanju v Ciudad de México in nazaj, vendar ne omenja nobene "prevare". To je tudi razumljivo. Iz Pimeríe se je odpravil 16. novembra in po sedmih tednih potovanja prispel v prestolnico 8. januarja 1696 - ravno dan, preden je bil imenovan Almonazirjev naslednik Juan de Palacios. Novi provincial pa je bil njegovemu delovanju v Pimeríi zelo naklonjen in gost je bil deležen "vse pozornosti in donacij novega očeta provinciala in njegovega predhodnika [...] in njegove ekscelence [podkralja] grofa de Galveja in gospe podkraljice«. Palacios mu je odobril tudi pet novih očetov za delo v Pimeríi. 8. februarja je Kino odšel iz Ciudad de Méxica in se sredi maja vrnil v misijon Nuestra Señora de los Dolores. Ko so »sinovi Pima« izvedeli za njegov prihod, so od daleč s severa in zahoda prišli poglavarji, da bi ga prosili za sveti krst in očete za ljudi v njihovih vaseh (Kino, I, V, I-II, 116-117).

Diego de Almonazir je o Kappusovih obremenilnih navedbah očitno poročal generalu Družbe v Rim in (tudi) z njimi utemeljil svoj prikriti »vzgojni« ukrep. Toda general Tirso González, Kinov osebni prijatelj, se z Almonazirjevim ravnanjem nikakor ni strinjal. To je jasno in hudomušno napisal novemu provincialu 28. junija 1696. V pismu izraža brezpogojno podporo Kinovemu apostolskemu delu med ljudstvom Pima in Palaciosu naroča, naj ga takoj pošlje nazaj in mu poleg tega odredi še pomočnike za njegovo raziskovanje poti v Kalifornijo. Najzanimivejši je tisti del pisma, v katerem Tirso González vzame v bran svojega prijatelja kljub njegovim (domnevnim) napakam in z dobro mero ironije odgovarja na Kappusove očitke, ne da bi pri tem razkril njegovo ime:

26 Ta del je posebej zanimiv za razumevanje kolonizatorske politike: na konkretnem primeru je prikazan sistem sodelovanja misijonov ter civilnih in vojaških oblasti. Kappus večkrat poudari, da je $v$ teh treh mesecih v pismih župana mesta Real de San Juan opozarjal, da se pustošenje širi proti drugim misijonom, in vztrajno prosil za vojaško pomoč. Ta je prišla $\mathrm{z}$ veliko zamudo. $\mathrm{V}$ času, ko to poroča, župan organizira novo vojaško posredovanje, a misijonar se zaskrbljeno sprašuje, kako se bo vsa ta nesreča končala. (Upor je bil dokončno zatrt 30. avgusta (gl. Kino, I, III, XIII in I, V, I)).

27 Nekateri so o tem in o njegovem zaščitniškem odnosu do upornikov med uporom pisali tudi na sedež Družbe v Rim (Gómez Padilla, 2007, 83; Ortega Noriega, del Río, 2010, 138). Kino v Favores večkrat omeni nenehna »spodbijanja in nasprotovanja« ter »zlonamerna poročila« neimenovanih nasprotnikov njegovih misijonarskih načrtov (npr. I, V, III, 117). 
Kinu lahko očitam dve poglavitni in hkrati edini stvari: prvič, da v svoji preveliki gorečnosti $\mathrm{z}$ veliko lahkoto podeljuje krst, ne da bi tiste, ki ga bodo prejeli, dovolj podučil. [...] A če je očetova gorečnost pri tem početju v čem čezmerna, ga bo opozorilo nadrejenih umirilo in bo svoje navdušenje prilagodil njihovim napotkom. Drugi očitek se poraja iz istega vzroka, in sicer da zaradi svoje velike gorečnosti tovarišem začenja presedati. Če naj presojamo na podlagi pričujoče pritožbe, ne moremo pritrditi njeni upravičenosti. Prvič, ker nismo prejeli niti besedice od nikogar, ki bi se pritoževal čezenj; drugič, ker noben ali komaj kateri misijonar v Indijah v svojih pismih govori $\mathrm{z}$ večjo častjo in spoštovanjem o tistih, ki delujejo tam, in izpričuje nežnejšo ljubezen iz dna duše. To pa je težko združljivo s postavko, da je z njimi v slabih odnosih in da se slabo razumejo.

Končujem z napotkom, da ga Vaša Reverenca pošlje nazaj v misijone; naj mu pustijo delovati quia iusto non est posita lex; prepričan sem, da je Oče zelo primeren izbranec Našega Gospoda za njegovo slavo v teh misijonih. ${ }^{28}$

\section{Sklep}

Marko Anton Kappus je bil del jezuitskega "projekta misijonov«, ko je bil ta v Novi Španiji v največjem razmahu. Brezpogojno je bil predan ideji o izgradnji boljše, idealne krščanske družbe, ki na starem svetu ni bila (več) mogoča, in vse svoje delovanje je podredil uresničevanju tega »svetega poslanstva«. V Novem svetu je prebil natanko polovico življenja in ni si težko zamišljati, da je življenje med novimi kristjani z vsemi radostmi in težavami zanj postalo edina resničnost, stari svet pa se mu je zdel le še kot davne sanje. Opažal je tudi škodljive vidike pokristjanjevanja - nedoslednosti misijonarjev pri sprejemanju staroselcev v krščansko občestvo ter vmešavanje kolonizatorjev in kolonialne politike v delovanje misijonov - in opozarjal nanje, vendar skoraj gotovo ni mogel slutiti, v kako dramatičnih okoliščinah se bo utopija, pri ustvarjanju katere je sodeloval, petdeset let po njegovi smrti razblinila. Če bi dočakal leto 1767 in z njim izgon jezuitskega reda $\mathrm{z}$ vseh ozemelj španskega kraljestva ter se vrnil v Evropo, bi morda kdaj nostalgično zapisal: »Novi svet se mi skoraj dozdeva kot stvar, o kateri se mi je pred davnim časom samo sanjalo.«

28 Eusebio Kino, Correspondencia del P. Kino con los generales de la Compañía de Jesús 1682-1707. Burrus, Ernest J. (ed.). México: Editorial Jus, 1961, 45-47. Nav. po: Gómez Padilla, 2007, 84-85. (Prev. M. Š.) Ta prigoda tudi ponazarja, kakšni so bili časovni intervali, v katerih je potovala pošta $\mathrm{z}$ ene strani Atlantika na drugo. Prejemnikov odziv je pogosto prispel, ko so bile okoliščine tako spremenjene, da ni bil več relevanten. Kino se je takrat, ko je Palacios prejel generalovo pismo, kot smo videli zgoraj, že vrnil v Pimerío. 


\section{Bibliografija}

Classen, A., The Scientific, Anthropological, Geological, and Geographic Exploration of Northern Mexico by Eighteenth-Century German Jesuit Missionaries. A Religious and Scientific Network of Multilingual Writers. With a Focus on Johann Nentuig and Marcus Antonius Kappus, Mitteilungen des Instituts für österreichische Geschichtsforschung 122/1, 2014, str. 40-61.

Concilios provinciales primero, y segundo, celebrados en la muy noble, y muy leal Ciudad de México (1769), https://archive.org/details/conciliosprovinc00cath [1. 5. 2017].

Gómez Padilla, G., Kino, un Xavier de las Indias occidentales, v: San Francisco Javier entre dos continentes (ur. Arellano Ayuso, I., González Acosta, A., Herrera, A.), Madrid, Frankfurt na Majni 2007, str. 71-87.

Hausberger, B., La violencia en la conquista espiritual: las misiones jesuitas de Sonora, Jahrbuch für Geschichte Lateinamerikas 30, 1993, str. 27-54.

Hausberger, B., Jesuiten aus Mitteleuropa im kolonialen Mexiko. Eine Bio-Bibliographie. Studien zur Geschichte und Kultur der Iberischen und Iberoamerikanischen Länder (vol. 2) (ur. Edelmayer, F., Kohler, A., Rueda Fernández, J. C.), Dunaj, München 1995.

Hausberger, B., La vida cotidiana de los misioneros jesuitas en el noroeste novohispano, Estudios de Historia Novohispana 17, 1997, str. 43-106.

Hausberger, B., Vida cotidiana en las misiones jesuitas en el noroeste de México, Iberoamericana 2/5, 2002, str. 121-135, http://journals.iai.spk-berlin.de/index. php/iberoamericana/article/view/483/168 [12. 4. 2017].

Hausberger, B., Miradas a la misión Jesuita en la Nueva España, México 2015.

Hernández y Sánchez-Barba, M., Estudio preliminar: Viajes misionales por la Primería Alta. Viajes por Norteamérica (ur. Ballesteros Gaibrois, M.), Madrid 1958, str. 89-94.

Kino, E. F., Flores (sic) celestiales de Jesús y María Santísima y del Gloriosísimo apóstol de las Yndias Francisco Xavier (ur. Hernández y Sánchez-Barba, M.). Viajes por Norteamérica (ur. Ballesteros Gaibrois, M.), Madrid 1958, str. 87-255.

Maver, I., Marko Anton Kappus (1657-1717) v kolonialni Ameriki, v: Stanonikov zbornik: študije in eseji s področja literarnih in sorodnih ved, 1, Ljubljana 2016, str. 57-103.

Nabergoj, T., A letter of Marcus Antonius Kappus to Eusebius Franciscus Kino (Sonora in 1690), Acta neophilologica 31, 1998, str. 65-80.

Nabergoj, T., A letter of Marcus Antonius Kappus to Eusebius Franciscus Kino (Sonora in 1690): appendix: facsimile, Acta neophilologica 32, 1999, str. 119-122. 
Nabergoj, T., Marko Anton Kappus (1657-1717): misijonar, ki je odkrival Mehiko, v: Vigenjc: Glasilo kovaškega muzeja v Kropi 9. Kropa 2009, str. 23-32, https://issuu. com/mropdf/docs/vigenjc_9_web [15.4.2017].

Nabergoj, T., Marcos Antonio Kappus (1657-1717), jesuita esloveno, misionero en el noroeste de México, v: Ponencias presentadas en el III Coloquio Internacional "La imagen de Hungría en Iberoamérica en el siglo XX" (ur. Fischer, F., Lilon, D.), Iberoamericana Quiqueecclesiensis 9, Pécs 2011, str. 313-318, http://www. academia.edu/2121992/Relaciones_de_estado_entre_M\%C3\%A9xico_y_ Europa_de_1945_hasta_la_actualidad [15.4.2017].

Navajas Josa, B., Aculturación y rebeliones en las fronteras americanas. Las misiones jesuitas en la Pimería y el Paraguay. Cuadernos Americanos Francisco de Vitoria 13, Madrid 2011, http://ddfv.ufv.es/bitstream/handle/10641/1054/definitivo\%20 LA\%20MISI\%C3\%93N\%20DE\%20FRONTERA\%20junio2010.pdf?sequence=1 [29. 5. 2017].

Ortega Noriega, S., Un ensayo de historia regional: El noroeste de México 1530-1880, México 1993.

Ortega Noriega, S., del Río, I. (ur.), Tres siglos de historia sonorense, 1530-1830, México 2010 [1985].

Ricard, R., La conquista espiritual de México (šp. prev. Garibay K., A. M.), México 1986 [1947].

Salmón, R. M., Indian Revolts in Northern New Spain: A Synthesis of Resistance, 16801786, Lanham, New York, London 1991.

Schwaller, J. F., La iglesia en la América colonial española. Historia general de América Latina: Consolidación del orden colonial (vol. III, t. 2) (ur. Castillero Calvo, A., Kuethe, A.), Pariz 2001, str. 543-574.

Stanonik, J., Letters of Marcus Antonius Kappus from colonial America I, Acta neophilologica 19, 1986, str. 33-57.

Stanonik, J., Letters of Marcus Antonius Kappus from colonial America II, Acta neophilologica 20, 1987, str. 25-38.

Stanonik, J., Letters of Marcus Antonius Kappus from colonial America III, Acta neophilologica 21, 1988, str. 3-9.

Stanonik, J., Letters of Marcus Antonius Kappus from colonial America IV, Acta neophilologica 22, 1989, str. 39-50.

Stanonik, J., Letters of Marcus Antonius Kappus from colonial America V, Acta neophilologica 23, 1990, str. 27-37.

Stanonik, J., Marcus Antonius Kappus: the first Slovenia-born poet in America, Acta neophilologica 28, 1995, str. 59-68. 
Stanonik, J., Letters of Marcus Antonius Kappus from colonial America VI, Acta neophilologica 30, 1997, str. 43-57.

Stanonik, J., Marcus Antonius Kappus: a reevaluation, Acta neophilologica 40/1-2, 2007, str. 61-74.

Torales Pacheco, M. C., Diversidad, unidad e identitades en la Provincia Mexicana de la Compañía de Jesús, v: Escritura, imaginación política y la Compañía de Jesús en América Latina [silogs XVI-XVIII] (ur. Coello de la Rosa, A., Hampe Martínez, T.), Barcelona 2011, str. 167-183.

Zaplotnik, I., Marko Anton Kappus: prvi slovenski misijonar v Ameriki / Mark Anton Kappus: The First Slovenian Missionary Explorer in America (ur. Rožič, P.), Ljubljana 2016. 


\section{Maja Šabec}

\section{Slovenski misijonar Marko Anton Kappus in pokristjanjevanje Nove Španije}

Ključne besede: Marko Anton Kappus, Nova Španija, jezuitski misijoni, 17. in 18. stoletje, pokristjanjevanje

Letos mineva 300 let od smrti prvega slovenskega misijonarja v Mehiki Marka Antona Kappusa. Jezuitski red, katerega član je bil, je odigral odločilno vlogo v procesu kolonizacije odročnih predelov na severu in severozahodu Nove Španije, saj je pokristjanjevanje potekalo hkrati in v soodvisnosti z ekspanzijo kolonialnega sistema.

Prispevek podrobneje osvetli pomen, ki so ga misijonarji pripisovali enemu temeljnih opravil svojega duhovnega poslanstva, podeljevanju krsta. Skozi pogled Marka Antona Kappusa se pokaže, v kako zelo različnih, negotovih, burnih, pogosto protislovnih razmerah so delovali, s kakšnimi objektivnimi in subjektivnimi izzivi so se srečevali ter kako globoka sta bila njihova vera in prepričanje $\mathrm{v}$ upravičenost svojega početja.

V tem kontekstu je zanimiva vsebina Kappusovega pisma provincialu Diegu de Almonazirju iz leta 1695, v katerem se izriše drugačen, doslej nepoznan odtenek v odnosu slovenskega jezuita do slovitega misijonarja, raziskovalca in kartografa Francisca Eusebia Kina. 
Maja Šabec

\section{The Slovenian missionary Marko Anton Kappus and the Christianisation of New Spain}

Keywords: Marko Anton Kappus, New Spain, Jesuit missions, $17^{\text {th }}$ and $18^{\text {th }}$ century, Christianisation

This year marks 300 years since the death of Marko Anton Kappus, the first Slovenian missionary to Mexico. The Jesuit order he belonged to played a decisive role in the colonisation of remote areas in the northern and north-western parts of New Mexico, since Christianisation took place simultaneously and in correlation with the expansion of the colonial system.

The paper sheds light on the importance the missionaries attributed to one of the fundamental rites of their spiritual mission, i.e. administering the sacrament of baptism. The perspective of Marko Anton Kappus shows the variety, insecurity, turbulence and often contradictory nature of the circumstances the missionaries worked in, the objective and subjective challenges they encountered, their devoted faith as well as their deep conviction that their deeds were justifiable.

In this context, it is interesting to look at the content of Kuppus' letter from 1695 to the Provincial Superior Diego de Almonazir, in which a different, hitherto unknown detail of the attitude of the Slovenian Jesuit towards Eusebio Francisco Kino, a renowned missionary, explorer and cartographer, is outlined. 